\title{
Sistemas explicativos do comportamento
}

\author{
Olavo de Faria Galvão \\ Marcus Bentes de Carvalho Neto \\ Universidade Federal do Pará
}

\begin{abstract}
Resumo
Sistemas explicativos do comportamento têm servido para o controle comportamental em todas as culturas. Na história da psicologia como uma disciplina da ciência moderna diretamente focalizada na questão do porquê das ações, modelos explicativos diferentes estão na base da heterogeneidade e divergência das "escolas". Sistemas alternativos convivem, representando na ciência do comportamento diferentes sistemas filosóficos. Dualismos, monismos, mecanicismos, idealismos, humanismos, positivismos, materialismos, pragmatismos, geraram fenomenologias, associacionismos, psicodinâmicas, gestaltismos, comportamentismos, cognitivismos, naturalismos, culturalismos. Ortogonalmente, ou quase, aos modelos, os métodos, indutivos, hipotético-dedutivos, experimentais, fornecem os contextos de validação intermodelos, permitindo a utilização, por um sistema, de conhecimento gerado em outro sistema. Os resultados de aplicações derivadas de cada sistema dificilmente podem ser avaliados comparativamente. A inserção sociopolítico-cultural dos adeptos de cada modelo, método, assume papel de característica do modelo, fator a ser considerado na elaboração de um quadro comparativo. A psicologia brasileira hoje é um caso interessante de interação dinâmica dos fatores enumerados, com modelos obtendo aceitação ou rejeição pela inserção social de seus seguidores, e seguidores obtendo aceitação ou rejeição social pela conceituação generalizada do modelo.
\end{abstract}

Palavras-chave: modelo; sistema, história da Psicologia.

\begin{abstract}
Explanatory systems of behavior

Explanatory systems of behavior have served for behavioral control in every culture. In the history of Psychology, as a modern discipline focused directly on causes of action, different explanatory systems are at the root of heterogeneity and divergence of "movements". Alternative systems coexist, representing differing philosophical systems in behavioral science. Dualisms, monisms, mechanicisms, idealisms, humanisms, positivisms, materialisms, pragmatisms generated phenomenologies, associationisms, psychodynamics, gestaltisms, behaviorisms, cognitivisms, naturalisms, culturalisms. Orthogonally, or almost so, to the systems, inductive, hypothetic-deductive, experimental methods advance inter-system validation contexts, allowing different systems to use knowledge gathered in other systems. Results from application of each system are difficult to evaluate comparatively. Socio-political-cultural insertion of followers of each system is elevated to take into consideration the role of characteristics of each system, for preparation of a comparative schedule. Brazilian Psychology today is an interesting example of dynamic interaction between the factors enumerated, with systems being accepted or rejected as result of the social insertion of their fellows, as a consequence of the generalized conceptualization of the system.
\end{abstract}

Keywords: system, movement; History of Psychology.

\section{I - Plano Geral do Ensaio}

Este texto focaliza um conjunto de tópicos possivelmente relevantes para quem pretende estudar história da psicologia, tratando do contexto ideológico no qual os estudiosos da psicologia viveram e vivem.

Não pretende ser exaustivo, apenas indicar algumas relações contextuais possíveis de serem feitas ao se refletir sobre modelos explicativos.

As interpretações gerais apresentadas terão certamente significados diferentes para cada ouvinte, dependendo de sua própria história, ou seja, do contexto em que interagiu com a psicologia como ciência.

O texto demonstra vieses dos autores em termos de modelos explicativos, e uma certa disponibilidade para modificá-los a partir de novas evidências e argumentos, considerando-se que a complexidade do objeto de estudo - ele mesmo ainda distante de um acordo generalizado - ainda está longe ser amplamente compreendida com nossos atuais modelos. Assim sendo, o texto não representa uma posição neutra e uma visão desinteressada, mas defende pontos de vista. 


\section{II - Sobre o Controle Comportamental e a Relação Entre Ciência e Religião}

Um primeiro ponto para reflexão é o de que modelos explicativos do comportamento têm servido para o controle comportamental em todas as culturas.

A ciência universitária atual é, ela mesma, como um todo, um sistema que tem por objetivo a previsão e o controle da natureza, concebida como um sistema dinâmico integrado, em que cada movimento pode sempre ser correlacionado a um outro ou a outros.

As diferentes especialidades correspondem a conjuntos de pressupostos e métodos adequados ao estudo de diferentes recortes da natureza, sendo a identidade como ciência preponderante sobre as peculiaridades como especialidade.

As especialidades, guardadas suas diferenças, são ciências porque guardam consistência interna, estabelecendo níveis de análise, definindo os tipos de eventos que se propõem a examinar e compreender, agrupando esses eventos em categorias integradas, relacionando entre si os grupos de eventos, inferindo processos gerais a partir de observações em condições definidas e, no caso das ciências experimentais, replicáveis.

Mesmo ocupada com aspectos específicos da natureza, cada especialidade desenvolve leis científicas exatamente para permitir aos homens lidarem de forma mais efetiva com aqueles aspectos da realidade. A teoria da evolução, por exemplo, permitiu analisar de forma nova as conseqüências das intervenções humanas na natureza.

Podemos, portanto, considerar que todas as especialidades visam controlar o comportamento dos homens ao lidar com a natureza (Galvão, 1980; Skinner, 1977). Melhores teorias não seriam aquelas que descrevessem a natureza de maneira mais perfeita, seriam aquelas que gerassem maior acordo sobre como lidar, conceitual e tecnicamente com a natureza. Os conceitos e as técnicas, de certa forma, criam a natureza ao modificarem a maneira como olhamos para os fenômenos e as relações entre eles (Coutinho, 1996a, 1996b).

$\mathrm{O}$ aspecto específico da natureza estudado pela ciência do comportamento é o que a distingue das demais ciências; ao visar a previsão e o controle do comportamento das pessoas ao lidarem com o comportamento delas próprias ou de outras pessoas. Outras disciplinas visam a previsão e o controle do comportamento das pessoas ao lidarem com outras partes da natureza.

A ciência se estrutura em torno de uma concepção materialista e monista, que se opõe, na história, ao saber religioso dualista. Vigora igualmente no pensamento científico um ateísmo metodológico, ou seja, todo e qualquer fenômeno é encarado como natural e regulado por eventos não transcendentais, eventos estritamente mundanos (Dawkins, 2000; Dennett, 1997; Sagan, 1996). Por mais incompreensível que pareça um fenômeno, a opção de explicá-lo atribuindo-o a uma força extranatural está fora de cogitação. A ciência se estruturou na história com o desenvolvimento do pensamento relacional, em que cada evento pode ser satisfatoriamente explicado quando são conhecidas as condições materiais de sua ocorrência. Identificar como dois ou mais conjuntos de eventos naturais/materiais, mais precisamente algumas de suas dimensões mensuráveis, estariam relacionados de forma correlacional ou funcional seria o cerne da atividade e, ao mesmo tempo, da explicação científica (Bachrach, 1975; Skinner, 1965).

Tal pensamento se distancia da explicação em termos de essências e tendências ou forças intrínsecas imateriais. Da mesma forma não apela para qualquer dimensão estranha ao universo físico para dar conta dos eventos sob exame.

Os estudiosos, os pesquisadores, enquanto cidadãos, entretanto, nem sempre são contagiados pela concepção materialista e monista da ciência, restringindo-se a serem cientistas exclusivamente materialistas e relacionais no campo de sua especialidade, mantendo concepções diferentes dos pressupostos da ciência, quando buscam conhecimento sobre outros campos, aceitando, por exemplo, explicações envolvendo entidades imateriais construídas dentro da lógica da verdade preexistente. A própria adoção de um ateísmo, apenas metodológico, circunscrito aos interesses de uma pesquisa particular do cientista, mas não generalizável para o seu universo como um todo, sinaliza o quanto o modo científico de interpretar o mundo foi afetado por pressupostos pré-científicos e compartimentações artificiais da realidade humana (Russell, 1969). Compartimentações estas que só fazem sentido em uma perspectiva ontológica dualista de mundo, em que supostas e convenientes fronteiras são erguidas sutilmente entre certos aspectos da experiência humana e outros. A realidade é cindida entre um plano dos eventos racionais e empiricamente conhecíveis, restritos ao natural e físico e o plano extradimensional da chamada espiritualidade, interpretada como um fenômeno metasocial, onde as categorias científicas não seriam aplicáveis, por supostamente inúteis para apreendê-la. Debates sobre a origem da vida, por exemplo, são ilustrativos do confronto entre as incertezas próprias da ciência e as certezas do pensamento doutrinário.

A contradição existe, porém é plenamente compreensível se levarmos em conta que o "cientista" não é uma entidade abstrata, forjado integralmente ou majoritariamente desde a tenra idade nas searas puras do racionalismo, do ceticismo e da exigência sistemática de evidências empíricas e lógicas sobre os eventos do mundo, mas sim, um indivíduo concreto com uma história particular de exposição a diversas práticas culturais, com raízes míticas, místicas e sobrenaturais. De fato, o método científico foi concebido originalmente como uma forma de disciplinar o conhecimento humano, purgando-o de suas distorções naturais, em uma espécie de tentativa de purificação do saber. Tanto Descartes quanto Bacon partiram exatamente da constatação que o homem guardaria limites intrínsecos de diversas ordens e que para construir um conhecimento válido 
seria imprescindível iniciar por conceber mecanismos de autocorreção poderosos: o método científico. No caso de Bacon (1997), os "ídolos" descritos no seu "Novum Organum" especificam exatamente tais limitações humanas, e sua proposição metodológica explora possíveis antídotos para cada um deles. Contudo, o próprio ensino de ciências no nível fundamental e secundário acaba trabalhando contra o pensamento científico ao apresentar a ciência não como uma postura interpretativa diante do mundo, mas como um avassalador conjunto de conteúdos prontos, irretocáveis, que devem ser incondicionalmente decorados para a próxima prova. Ao invés de se perguntar sobre como buscar ordem na natureza, listam-se os constituintes básicos da natureza, que os alunos precisam decorar, reduzindo a tabela periódica, por exemplo, de uma ordenação com base em mensurações, a um mosaico sem relações entre suas partes além do fato de estarem juntas. A ciência assim ensinada é apenas mais um dogma a ser acolhido com fé. Não há nada que a diferencie das práticas místicas rígidas com as quais o mesmo aluno tem contato desde cedo. Acrescente-se a isso o fato de muito raramente uma criança em idade pré-escolar estar de alguma forma inserida em contextos que ofereçam alternativas não-religiosas ou místicas de explicações e, mais ainda, de como buscar por si mesmo tais explicações do mundo no próprio mundo.

O desenvolvimento científico e a adoção da ciência como uma instituição apoiada pela sociedade e pelos estados, entretanto, deveu-se justamente ao seu caráter materialista e monista, que encontrou eco em uma sociedade em vias de industrialização, e as descobertas científicas colocavam em xeque dogmas religiosos.

Contraditoriamente, na ciência, como uma instituição da pergunta, das respostas provisórias, da dúvida como método e das suposições como ferramentas em contínuo teste, coexistem teorias com inspiração essencialista e dualista, mas que, ao adotarem o método da observação sistemática como meio de acesso indireto a suas suposições teóricas, produzem dados positivos que podem ser levados em conta por estudiosos de outros sistemas teóricos. Entidades imateriais são parte de alguns modelos explicativos que, em outros aspectos, obedecem ao método científico. $\mathrm{O}$ desenvolvimento das disciplinas coincide com o abandono, mais ou menos gradual, de teorias baseadas em propriedades invisíveis, cuja variabilidade explica a variabilidade no mundo visível (Kuhn, 1975)

Como em relação a outras instituições, no que concerne à ciência, a sociedade adotou essa nova forma de saber mantendo outras, mesmo contraditórias entre si. Nos regimes políticos, por exemplo, podem conviver em uma mesma nação concepções contraditórias de estruturação do poder, e há inclusive um aforismo que reza que "a unanimidade é burra”. A pluralidade é vista nesses contextos como uma virtude em si mesma e a busca de um critério único mais eficaz de avaliação dos discursos sobre o mundo como uma ação injustificável. O maniqueísmo é mais facilmente entendido, não necessariamente justificado, em países recém saídos de ditaduras militares ou expostos aos males de ideologias monolíticas (como as nazistas, fascistas e socialistas "reais"). A defesa intransigente da pluralidade possui nesses espaços significados poderosos, com forte conteúdo emotivo, mas deveria ser complementada pela avaliação dos espaços diferenciados que cada opção implica (que acaba por limitar a possibilidade de um diálogo crítico racional sobre critérios universais de verdade [a expressão "critérios universais de verdade" denota a possibilidade de uma verdade universal, quando cada opção é uma forma de agir sobre o mundo]).

Como a ciência vai além da sua utilidade no desenvolvimento de tecnologias específicas, e coloca-se como um sistema explicativo em perspectiva para todas as circunstâncias, ela compete diretamente com as religiões, que se baseiam em articulações de normas de conduta e sistema explicativo, em que pese a existência de propostas conciliatórias.

Dialeticamente, as sociedades tinham razões práticas para aceitar tanto a ciência como a religião, e o conflito entre os dois sistemas, inicialmente aberto e espetacular, principalmente devido ao objetivo perseguido pela Igreja, de eliminar o sistema alternativo, inclusive seus representantes, foi sendo reduzido a escaramuças verbais em questões de conflito de fundo como a origem do universo e da vida, enquanto se aceita como normal freqüentar a universidade e a igreja.

Em ambas as instituições surgiram pensadores propondo soluções de convivência, estabelecendo formas de interpretação não antagônicas dos princípios de ambas, que resultou, na Igreja, no surgimento da diferenciação entre literais ou fundamentalistas, e modernos, e, similarmente, na ciência, ocorre a definição de limites para o conhecimento científico, cujo escopo ficaria aquém de questões como a da espiritualidade e a liberdade de escolha, campos da religião e da ética.

Em ambas as instituições, na ciência e na religião, o controle comportamental era e é um objetivo. Se as escrituras prescrevem as condutas aceitáveis e as razões para elas, as leis científicas governam o olhar, conectando entre si partes da natureza cuja relação muito dificilmente poderia ser inferida sem o uso de conceitos e métodos precisos e longamente desenvolvidos e aperfeiçoados.

Para encerrar esse tópico ressalta-se apenas que, do ponto de vista da ciência, a adoção de uma forma de saber é resultante de processos culturais de padronização e diferenciação que muito dificilmente podem resultar em unanimidade. Noutras palavras, assim como duas escrituras podem estar em desacordo, dois argumentos científicos também podem. A diferença é a de que a discordância científica se modifica com a evolução proporcionada por novas pesquisas e novas descobertas que venham a esclarecer aspectos desconhecidos quando da época da divergência. A unanimidade e a pluralidade são momentos históricos que refletem o caráter social do empreendimento científico. O que satisfaz diferentes 
grupos depende da interação complexa de fatores, principalmente históricos, e as traduções das explicações de um sistema nas bases de outro sistema evidenciam tanto convergências como divergências conceituais.

\section{III - Sobre os Sistemas Explicativos em Psicologia}

$\mathrm{Na}$ ciência moderna, os sistemas explicativos marcaram a história da psicologia.

Podemos considerar que o desenvolvimento da psicologia foi extremamente marcado pela indefinição entre o monismo e o dualismo (Keller, 1974; Marx, \& Hillix, 1993; Politzer, 1975), e que a cada sistema filosófico correspondeu um desenvolvimento especulativo na psicologia, com seu método correspondente. Podemos considerar, também, que a ciência moderna se desenvolveu com o uso do método indutivo, partindo do estabelecimento de relações específicas, medidas em condições controladas, para a definição de leis gerais (Teixeira, 2000).

O modelo hipotético dedutivo, por sua aplicabilidade na lógica e na matemática, entretanto, foi, ainda é, usado no desenvolvimento de teorias psicológicas dualistas, propondo relações causais entre estruturas mentais inferidas e comportamentos publicamente observáveis.

Do nosso ponto de vista, a construção teórica hipotético-dedutiva, por partir de postulados irredutíveis, leva, entre outras conseqüências, a teorias diferentes para cada pensador, em função dos postulados e das articulações entre esses postulados adotados, e, diferentemente das proposições em um sistema que adota o método indutivo, cuja validação depende de medidas relacionais, depende apenas da consistência interna dos modelos propostos.

A aceitação da psicologia como ciência do comportamento reflete muito mais um acordo metodológico em torno de protocolos mínimos para que uma pesquisa seja considerada científica, do que concordância quanto aos limites conceituais. Ter o comportamento como fonte primordial de dados psicológicos não implica sua adoção como objeto em si mesmo e muito menos uma definição inequívoca das variáveis relevantes que deveriam explicá-lo, como bem atestam as versões contemporâneas de mentalismo, historicamente agregadas sob o rótulo genérico de "cognitivismo" (Uttall, 2000).

E não existe um quadro fixo que nos aponte as formas adequadas e as inadequadas de pensar, porque as inferências válidas em um sistema teórico ou em uma época histórica podem ser consideradas inválidas em outro sistema ou época.

Modelos alternativos convivem, representando na ciência do comportamento diferentes sistemas filosóficos. Dualismos, monismos, mecanicismos, idealismos, humanismos, positivismos, materialismos, pragmatismos, geraram fenomenologias, associacionismos, psicodinâmicas, gestaltismos, comportamentismos, cognitivismos, naturalismos, culturalismos.
Para compreender a psicologia, tentamos entender as vinculações das teorias e sistemas da psicologia a escolas filosóficas, e estas categorização e vinculação das teorias são um trabalho de interpretação e contextualização dificultado pela diversidade e nuances das tendências filosóficas e dos muitos distintos aspectos que podem ser examinados em cada teoria em particular.

Termos como positivismo, por exemplo, foram usados para caracterizar movimentos amplamente antagônicos, mas que comungavam uma característica central de que a ciência se constrói pela proposição e não pela crítica. Só gera confusão, por exemplo, colocar juntos o positivismo de Comte, doutrinário e organizado em torno de disciplinas e categorias sociais hierárquicas, e o positivismo do Círculo de Viena, construído em torno da discussão intensa de propostas a respeito do caráter da ciência, e do significado de seus conceitos mais genéricos como teoria, método, natureza dos eventos e das relações, critérios de verdade e de refutação de teorias (para um exame crítico do uso simplista que o termo toma nas discussões acadêmicas, especialmente nas ciências humanas e sociais, ver Cupani, 1990, Gomes, 1987). Similarmente, o termo behaviorismo foi usado como autodenominação por grupos de pesquisadores na psicologia e em outras ciências humanas, em geral complementado por prefixos ou qualificativos (protobehaviorismo, behaviorismo watsoniano, neobehaviorismo, behaviorismo metodológico, behaviorismo radical). Cada denominação refere-se a tradições de pesquisa com divergências palpáveis em seus critérios de cientificidade (Carrara, 1998; Day, 1980).

Ortogonalmente, ou quase, aos modelos, os métodos, indutivos, hipotético-dedutivos, experimentais, fornecem os contextos de validação inter-modelos, permitindo a utilização por um sistema de conhecimento gerado em outro sistema.

$\mathrm{O}$ intercâmbio de dados entre tradições de pesquisa antagônicas é uma prática cada vez mais importante para os pesquisadores, provavelmente porque independentemente da teoria que justifica o estudo, o acesso aos dados obtidos em condições controladas e bem descritas permite o exercício da indução em outro contexto de estudo.

Os resultados de aplicações derivadas de cada sistema podem ser avaliados comparativamente nos casos em que a sociedade tem indicadores independentes reconhecidos e definição clara dos problemas abrangidos. Questões comportamentais complexas como a relação entre a observação da violência e sua prática, como problemas de relacionamento entre pessoas, para as quais dispomos apenas de correlações estatísticas imprecisas, e que muito provavelmente envolvem grande número de variáveis e alto grau de diferenciação individual, tem sido campo para o exercício de interpretações que assumem ares de científicas e que não passam de especulações que, quando muito, não se afastam do bom senso comum. 
A ciência indutiva se constrói paulatinamente, enquanto sistemas hipotético- dedutivos são fórmulas interpretativas prontas. No entanto é comum ver-se o uso de conceitos indutivos como fórmulas interpretativas prontas, como foi bem o caso da redução da análise do comportamento à fórmula da contingência, por muitos anos (Galvão, 1983).

\section{IV - Sobre Posições Políticas e Práticas Científicas}

A inserção sociopolítico-cultural dos adeptos de cada modelo, de cada método, assume papel de característica do modelo dificultando mais a elaboração de um quadro comparativo simplificado.

A queda do muro de Berlim, em 1989, com o fracasso da experiência soviética, determinou o abandono da dialética materialista por um grande número de intelectuais, e o aparecimento em cena de teóricos do estado mínimo. Esse exemplo mostra que as consequiências práticas dos modelos retroagem sobre os modelos, seja sobre sua articulação conceitual interna, seja sobre seu status em cada geração intelectual.

O positivismo de Comte foi a doutrina que emulou os intelectuais brasileiros do movimento republicano, e o correspondente liberalismo fez frente simultaneamente aos movimentos internacionalista comunista e nacionalista fascista.

Claro está que a história coloca os movimentos científicos ora à esquerda, em defesa das maiorias, ora à direita, em defesa das elites, dos movimentos sociais.

A psicanálise foi associada à esquerda nos anos 30 do século $\mathrm{XX}$, na Europa, por alguns de seus proponentes, como Adler e Adorno, trazendo à baila a discussão da repressão da mulher e do tabu em torno dos assuntos relacionados ao relacionamento sexual, em que pese o machismo de Freud.

O behaviorismo skinneriano foi associado, no Brasil, nos anos sessenta, à resistência contra o regime militar, porque o Instituto de Psicologia da UnB, então organizado por analistas comportamentais, em peso, juntamente com muitos outros, pediu demissão quando da intervenção militar naquela universidade.

Pode-se dizer que os movimentos científicos não são, por sua própria articulação teórica, de direita ou de esquerda, ainda que, na verdade, quanto maior o poder tecnológico gerado por uma especialidade científica, mais se espera sua vinculação ao estado em uma determinada nação e fase histórica. Noutras palavras, os modelos adotados pelos cientistas que fazem parte do establishment são provavelmente consistentes com as políticas vigentes. Nos dias atuais as pesquisas genéticas ultrapassaram em apoio financeiro as pesquisas de novos materiais e tecnologia espacial e de armamentos dos últimos quarenta anos do século $\mathrm{XX}$, possivelmente por sua relevância para o domínio comercial mundial. Digamos que a ciência é sempre candidata a aliada do status quo e que, no entanto, por seu caráter questionador, é sempre aceita com reservas pelo poder, e mantida como subalterna.

\section{V - Sobre a Psicologia Brasileira Contemporânea}

A psicologia brasileira hoje é um caso interessante de interação dinâmica dos fatores enumerados e de outros, com modelos obtendo aceitação ou rejeição pela inserção social de seus seguidores e seguidores obtendo aceitação ou rejeição social pela conceituação generalizada do modelo.

A psicologia brasileira ainda tem muitas das feições da psicologia americana da década de 50 do século XX. A coincidência entre muitos títulos de disciplinas na grade curricular e capítulos de manuais dessa época não é apenas coincidência. A profissão foi criada em 1960, e o sistema de pós-graduação brasileiro começa em 1970, com crescimento muito lento no número de pesquisadores ativos, com formação e atuação baseada em diferentes modelos explicativos, dos quais os preponderantes foram a psicologia experimental animal, a psicanálise, a psicologia clínica em diferentes abordagens, a psicologia social, a psicologia da aprendizagem humana (escolar, educacional) e a psicologia do desenvolvimento. A prática profissional dos psicólogos continuou dependendo fundamentalmente de produção científica e desenvolvimento tecnológico estrangeiros.

O corpo docente das escolas de psicologia continua em sua maioria repassando conhecimento produzido alhures, com dificuldade crescente de formar estudantes atualizados quanto aos desenvolvimentos recentes nas diferentes áreas e modelos. A produção nacional de livros de psicologia é grande em títulos, mas não em tiragem, pois os cerca de quinhentos a três mil exemplares de uma edição brasileira não atingem o público leitor de mais de cem mil psicólogos e 140 cursos de Psicologia.

Os universitários formam uma categoria heterogênea de intelectuais. Existem aqueles para quem o curso universitário foi pouco mais que a conquista de um diploma e status de pessoa qualificada para tarefas genericamente relacionadas à leitura e escrita, e para as quais a função profissional exercida tem pouca relação direta com a especialidade de sua formação. Para esses os modelos explicativos não passam de entidades acadêmicas a que tiveram acesso limitado nas disciplinas cursadas nos tempos de estudante.

Mas qual é o ponto central desse assunto, quando falamos de modelos explicativos?

O ponto central é o de que estamos falando de modos de pensar.

Se um estudante desenvolve o modo de pensar científico, portanto relacional, monista e materialista, ele poderá, ao longo de sua vida, ir entendendo cada vez mais as nuances das relações entre o seu e os diferentes modos de pensar, enquanto busca ordem no universo.

Se um estudante adota um modo de pensar dualista, essencialista, então fará relações de cada aspecto circunstancial do mundo com a essência 
correspondente, e o universo conterá uma diversidade arbitrária dada a priori.

O sistema escolar não forma nos estudantes, necessariamente, o modo de pensar científico, de tal modo que os profissionais eventualmente adotam procedimentos que podemos caracterizar como de seguir receitas, ao invés de se perguntarem por quê, e buscarem as relações dos casos particulares com processos genéricos. $O$ hábito da atualização pode auxiliar na relativização do conhecimento científico e tecnológico apresentado nos manuais, que é sempre incompleto e provisório e a lidar mais tranquilamente com a incompletude intrínseca do saber científico, pois essa aparente fragilidade é, na verdade, a maior força do empreendimento científico. A permanente atualização pode, ainda, guindar o estudante e o profissional do papel de expectador informado, de mero consumidor esclarecido de conhecimento para a função ativa de (co) produtor de conhecimento.

\section{REFERÊNCIAS}

Bachrach, A. J. (1975). Introdução à pesquisa psicológica (4 ${ }^{\text {a }}$ reimp.). São Paulo: EPU.

Bacon, F. (1997). Novum Organum. Em Bacon, Coleção Os Pensadores. São Paulo: Nova Cultural.

Carrara, K. (1998). Behaviorismo radical: crítica $e$ metacrítica. Marília: UNESP Marília Publicações.

Coutinho, A. R. (1996a). Cientificidade e relevância social - I: Controvérsias sobre a cientificidade da Psicologia e das Ciências Sociais. Psicologia: Teoria \& Pesquisa, 12, 23-37.

Coutinho, A. R. (1996b). Cientificidade e relevância social - II: Uma rediscussão da questão da cientificidade e suas implicações sociais. Psicologia: Teoria \& Pesquisa, 12, 165-177.

Cupani, A. (1990). Positivismo, "positivismo" e objetividade científica. Reflexão, 46, 103-107.

Dawkins, R. (2000). Desvendando o arco-íris: ciência, ilusão e encantamento. São Paulo: Companhia das Letras.

Day, W. F. (1980). The historical antecedents of contemporary behaviorism. Em R. W. Rieber \& K. Salzinger (Eds), Psychology: theoretical-historical perspectives (203-262). New York: Academic Press.

Dennett, D. C. (1997). Fé na verdade. Disputatio, 3. Obtido em 23 de julho de 2003 do World Wide Web: http://www.disputatio.com/articles/003-1.pdf.

Galvão, O. F. (1980). Invenção e descoberta em psicologia. Psicologia, 6 (3), 13-19.

Galvão, O. F. (1983) A história do comportamento. Em R. Gorayeb (Org.), Anais da XIII Reunião Anual de Psicologia (pp. 288-315). Ribeirão Preto, SP: Sociedade de Psicologia de Ribeirão Preto.

Gomes, N. G. (1987) Considerações filosóficas sobre o positivismo e o estudo do comportamento. Em D. G. Souza; V. R. L. Otero \& Z. M. M. B. Alves (Orgs.), Anais da XVII Reunião Anual de Psicologia (pp. 423431). Ribeirão Preto, SP: Sociedade de Psicologia de Ribeirão Preto.

Keller, F. S. (1974). A definição da psicologia: uma introdução aos sistemas psicológicos ( $3^{\mathrm{a}}$ reimp.). São Paulo: EPU.

Kuhn, T. S. (1975). A estrutura das revoluções científicas. São Paulo: Perspectiva.
Marx, M. H. \& Hillix, W.A. (1993). Sistemas e teorias em psicologia. São Paulo: Cultrix.

Politzer, G. (1975). Crítica dos fundamentos da psicologia I. Lisboa: Editorial Presença.

Russell, B. (1969). A perspectiva científica. ( $3^{\mathrm{a}}$ ed.). São Paulo: Companhia Editorial Nacional.

Sagan, C. (1996). O mundo assombrado pelos demônios. São Paulo: Companhia das Letras.

Skinner, B. F. (1965). Science and human behavior. New York: The Free Press.

Skinner, B. F. (1977). Why I am not a cognitive psychologist. Behaviorism, 5, 1-10.

Teixeira, J. F. (2000). Mente, cérebro e cognição. Petrópolis: Vozes.

Uttal, W. R. (2000). The war between mentalism and behaviorism: on the accessibility of mental processes. Mahwah, New Jersey: Lawrence Erlbaum Associates.

Recebido: 09.07.2003

Revisado:30.07.2003

Aceito:10.08.2003 


\section{Sobre os autores}

Olavo de Faria Galvão: Prof. Adjunto IV. Departamento de Psicologia Experimental, Programa de Pós-Graduação em Teoria \& Pesquisa do Comportamento, UFPA. Pesquisador 2A CNPq.

Endereço para correspondência: Trav. Castelo Branco 1.116 Apto. 1.004. São Brás. Belém-PA. CEP: 66063-080.

E-mail: ofg@cpgp.ufpa.br.

Marcus Bentes de Carvalho Neto: Prof. Adjunto I. Departamento de Psicologia Experimental, Programa de Pós-Graduação em Teoria \& Pesquisa do Comportamento, UFPA.

Endereço para correspondência: Rua João Canuto, 510. Centro. Ananindeua-PA. CEP: 67030-130.

E-mail: mbcn@cpgp.ufpa.br 